\title{
Naltrexone reduces ethanol- and sucrose-reinforced responding in rhesus monkeys
}

\begin{abstract}
These experiments evaluated the ability of naltrexone (NTX) to reduce selectively oral and IV ethanol-reinforced responding, and examined the ethanolNTX interaction in terms of the competitive opioid antagonist property of NTX. Five rhesus monkeys self-administered ethanol or sucrose and concurrently available water. Ethanol concentration was varied from $0.25 \%$ to $8 \%(\mathrm{w} / \mathrm{v})$. Naltrexone $(0.032-0.32 \mathrm{mg} / \mathrm{kg}$ ) or saline was given IM 30 min prior to some drinking sessions. NTX $(0.32 \mathrm{mg} / \mathrm{kg})$ reduced ethanol-reinforced responding at the concentration that maintained the most responding $(1 \%$ or $2 \%)$. NTX $(0.1 \mathrm{mg} / \mathrm{kg})$ reduced ethanol-reinforced responding, both at a low ethanol concentration $(0.25 \%)$ that produced little ethanol intake $(\mathrm{g} / \mathrm{kg})$, and at a higher concentration (4\%) with an appreciable intake. Thus, NTX $(0.1 \mathrm{mg} / \mathrm{kg})$ shifted the ethanol concentration-consumption curve down, in an insurmountable manner. NTX $(0.1$ and $0.32 \mathrm{mg} / \mathrm{kg})$ also reduced reinforced responding for sucrose $100 \mathrm{~g} / \mathrm{l}$. In another experiment, three rhesus monkeys were given opportunities to self-administer ethanol IV. NTX $(0.1 \mathrm{mg} / \mathrm{kg})$ reduced the number of ethanol injections obtained by the monkeys at all ethanol doses tested $(0.01,0.032$, and $0.1 \mathrm{~g} / \mathrm{kg}$ per injection).The dose-effect curve was also shifted down. These results showed that NTX reduced behavior maintained by either ethanol or sucrose non-selectively. Furthermore, the ability of NTX to suppress ethanol-reinforced responding did not depend on the route of ethanol administration and was not overcome by increasing the concentration or dose per injection of ethanol.
\end{abstract}

Key words Opioid antagonists · Oral self-administration · Intravenous self-administration · Alcohol · Operant behavior

K.L. Williams $(\varangle) \cdot$ J.H. Woods

1301 MSRB III, Department of Pharmacology,

University of Michigan, Ann Arbor, MI 48109-0632, USA

G. Winger · E.D. Pakarinen · J.H. Woods

Department of Pharmacology, University of Michigan, Ann Arbor, MI 48109-0632, USA

\section{Introduction}

In clinical studies of alcohol abusers, the opiate antagonist, naltrexone (NTX), was effective in reducing craving and relapse rates (O'Malley et al. 1992; Volpicelli et al. 1992). Self-reports from alcoholics indicate that NTX reduces the subjective "high" produced by alcohol consumption (Volpicelli et al. 1995). Given the success in clinical trials, NTX has been approved by the FDA and is being used as an adjunct in the treatment of alcoholdependent patients.

In preclinical studies, NTX and other opioid antagonists reduced ethanol drinking in rats and monkeys. For example, some experiments with rats reported that naloxone (NX) selectively reduced ethanol drinking when water was concurrently available (De Witte 1984;. Froehlich et al. 1990). Others showed in monkeys that NTX decreased the oral consumption of ethanol in a dose-dependent manner; less consistent decreases were observed on consumption of concurrently available water (Myers et al. 1986; Kornet et al. 1991).

Opioid antagonists reduced consumption when ethanol was offered by other routes of self-administration. In rats, NX pretreatment decreased responding for intragastric infusions of ethanol (Sinden et al. 1983). Altshuler et al. (1980) showed that NTX reduced IV self-administration of ethanol by rhesus monkeys. Thus, opioid antagonists reduced ethanol consumption regardless of the route of self-administration.

The effects of opioid antagonists appear not specific for ethanol. Early studies demonstrated that NX reduced feeding, water consumption, and sucrose drinking in rats (Holtzman 1974; Maickel et al. 1977; Stapleton et al. 1979). In other studies, opioid antagonists (NX, NTX, and diprenorphine) decreased the consumption of water, as well as sweetened condensed milk in monkeys (Brown and Holtzman 1981; Locke et al. 1982). These effects were produced in food-deprived and non-deprived animals. This evidence suggests that opioid antagonists are effective in decreasing ethanol consumption 
through a mechanism that modulates fluid or food consumption in general.

Opioid antagonists might modulate the palatability of food and fluid. Cooper and Turkish (1989) found, in rats, that NTX reduced consumption of palatable food (chocolate chips) and increased consumption of normal lab chow. NX has been shown to reduce the sham-feeding of a sucrose solution in rats, which was reversed by increasing the concentration of sucrose during the session (Kirkham and Cooper 1988b). In humans, NTX reduced the ratings of pleasantness of some foods (Fantino et al. 1986; Bertino et al. 1991). These studies suggest that opioid antagonists regulate food intake via effects on palatability or rewarding qualities of foods.

NTX and NX may reduce consumption of ethanol, food, and other palatable fluids by their common mechanism of competitive opioid antagonism. These antagonist effects are stereoselective as indicated by studies in which the inactive NX stereoisomer had no effect on consumption (Brown and Holtzman 1980; Kirkham and Cooper 1988a). One of these studies (Brown and Holtzman 1980) rank-ordered the potency of various antagonists (NX, NTX, diprenorphine, levallorphan, oxilorphan, and nalorphine) in their ability to suppress water intake. This rank-ordering corresponded with the rank-order of the antagonists' ability to precipitate morphine withdrawal in mice. Thus, the effects of opioid antagonists on consumption are probably mediated by an opioid receptor mechanism. In other assays, such as antinociception, these opioid antagonists interact with opioid agonists in a competitive manner such that the effect of the antagonist can be surmounted by increasing the dose of the agonist (e.g., Winger et al. 1992). If the effects of the antagonists on ethanol consumption are mediated by this opioid mechanism, it should be possible to overcome the antagonist effects by increasing the ethanol (dose or concentration).

The purpose of this study was to replicate the finding in monkeys that NTX reduced the oral and IV self-administration of ethanol. We were also interested in determining if the NTX effects were surmountable by increasing the concentration of ethanol, which increases the total ethanol dose consumed. Another aim of the current study was to compare the ability of NTX to modify oral ethanol consumption with its ability to modify an orally administered non-drug reinforcer (sucrose) in the same monkeys.

\section{Materials and methods}

Experiment 1: oral self-administration

Subjects

Subjects were five adult rhesus monkeys (Macaca mulatta; one female weighing 6-7 kg and four males weighing 7-11 kg) maintained at approximately $80 \%$ of their free-feeding weights. The monkeys previously had been subjects in studies of the oral reinforcing effects of the $m u$-opioid agonist, etonitazene, and the noncompetitive NMDA antagonist, phencyclidine. In both experiments 1 and 2, the "Guide for the Care and Use of Laboratory Animals" (NIH publication, vol. 25, number 28, revised 1996) was followed.

\section{Apparatus}

The animal housing room was on a 12-h light/dark cycle (lights on at 0700 hours, lights off at 1900 hours). The monkeys were housed in individual cages measuring $64 \mathrm{~cm} \times 72 \mathrm{~cm} \times 85 \mathrm{~cm}$ high. A fluid-delivery panel, similar to that used in other studies (Meisch et al. 1975; Henningfield and Meisch 1976), was attached to one wall of each cage during daily sessions. Holes were cut in the cage wall so that two brass spouts on the fluid-delivery panel protruded into the cage $50 \mathrm{~cm}$ from the floor. A stimulus light that could be illuminated red or green was located $3 \mathrm{~cm}$ above each spout. The drinking solutions were contained in $1000 \mathrm{ml}$ plastic bottles attached to the back of the panel. Plastic tubing connected each bottle to the spout valve. The fluid containers were elevated so that the liquid was gravity-fed to the spout valve and delivery was controlled by a solenoid switch. Contact with either spout closed an electrical circuit (drinkometer) and a response was recorded. The stimulus light above the spout flashed the appropriate color (green or red, depending on the fluid available) when contact was made with the spout. When the reinforcement schedule was satisfied, the solenoid was activated and $0.5 \mathrm{ml}$ fluid was delivered. Solutions were measured after the session using graduated cylinders to confirm delivery amounts. The experiments were controlled and the data recorded using IBM PCjr microcomputers located in a room adjacent to the housing room.

\section{Procedure}

Experimental sessions were conducted each day. Each session lasted $3 \mathrm{~h}$, during which the animal could respond and obtain either ethanol or concurrently available water. The ethanol was available under one colored stimulus light condition, and water was available under another. Three monkeys (CH966, RC186, and $\mathrm{CH} 942$ ) received the drug under the green stimulus light condition, whereas two monkeys $(058 \mathrm{~F}$ and $\mathrm{CH} 899)$ received the drug under the red stimulus light condition. The reinforcement schedule, fixed ratio 4 (FR4), operated concurrently and independently on each of the two spouts such that the responses on one spout did not alter the number of responses required for reinforcement on the opposite spout. Water was always available during the session from one of the spouts. The animals were fed after the session.

Several concentrations of ethanol $(0.25-8 \%)$ were tested concurrently with water. The ethanol concentration that maintained the greatest amount of behavior (defined by the number of fluid deliveries) is referred to as the peak concentration. The peak concentration was different for various subjects. For three monkeys (CH966, RC186, CH942) it was $1 \%$, while for the other two monkeys $(\mathrm{CH} 899, \mathrm{O} 58 \mathrm{~F})$ it was $2 \%$. The peak concentrations were made available following NTX administration in order to evaluate the effects of NTX in a condition where a large amount of behavior was observable. On test sessions, the monkeys were given a single IM injection of either NTX or saline 30 min prior to the start of a drinking session. During this phase of the experiment, each monkey received a total of ten injections (two saline, two NTX $0.032 \mathrm{mg} / \mathrm{kg}$, four NTX $0.1 \mathrm{mg} / \mathrm{kg}$, and two NTX $0.32 \mathrm{mg} / \mathrm{kg}$ ). The NTX doses were tested in the following order: $0.1 \mathrm{mg} / \mathrm{kg}, 0.032 \mathrm{mg} / \mathrm{kg}$, and $0.32 \mathrm{mg} / \mathrm{kg}$. The saline injections were given on days preceding the first NTX tests, and each NTX dose was separated by 3-7 days of non-injection drinking sessions. NTX $0.1 \mathrm{mg} / \mathrm{kg}$ was also tested in monkeys that had $0.25 \%$ or $4 \%$ ethanol available. NTX was tested twice at each of these ethanol concentrations. Saline injections were not given prior to either of these ethanol concentrations.

After a monkey had been evaluated with each dose of NTX in the ethanol-drinking phase of the study, the experiment was repeated with sucrose and water available concurrently. Initially, consumption of sucrose (3.2-100 g/l), available concurrently with water, was measured in each monkey. Duplicate observations of the effects of 0.1 and $0.32 \mathrm{mg} / \mathrm{kg}$ NTX were made on sucrose drinking at the concentration $(100 \mathrm{~g} / \mathrm{l})$ that maintained the greatest amount of behavior. A total of four saline injections were given, separated by 3-4 days. Two of these saline injections were given during the interval ( 2 weeks) between the first and second dose of 
NTX $0.1 \mathrm{mg} / \mathrm{kg}$, and the other two saline injections were given during the interval (1 week) between the first and second dose of NTX $0.32 \mathrm{mg} / \mathrm{kg}$.

\section{Data analysis}

Each monkey's average data (fluid deliveries, intake in $\mathrm{g} / \mathrm{kg}$, and fluid deliveries expressed as percentage of non-injection baseline), were used to calculate the mean and standard error of the mean for the group of monkeys. Most of the data are presented as the mean and standard error of the mean of the group data $(n=5)$.

For the fluid delivery data in which ethanol and water were available over various ethanol concentrations, the data were analyzed using a two-way repeated measures ANOVA on two factors. We tested for a effect of solution (ethanol versus water), and an interaction of solution and ethanol concentration. When significant differences were detected, a post-hoc Student Newman Keuls test was conducted for all pairwise comparisons of ethanol versus water. For the fluid delivery data in which different doses of NTX were tested at the peak ethanol concentration, the data were analyzed using a two-way repeated measures ANOVA on two factors. The data for the peak concentration are represented in the figures at the point on the $\mathrm{x}$-axis labeled $1 \%$ or $2 \%$ ethanol. The applied analysis tested for an effect of treatment (non-injection baseline, saline, $0.032 \mathrm{mg} / \mathrm{kg}$ NTX, etc.) and an interaction of solution and treatment. For the effect of treatment, a post-hoc Dunnett's test was applied, with saline as the control. The intake data were analyzed using a one-way repeated measures ANOVA. For post-hoc multiple comparisons on the intake data, we used a Dunnett's test with saline as the control. Similar analyses were applied to the data when sucrose was used instead of ethanol. For the interaction effect (solution and treatment), a post-hoc SNK was used. When the fluid deliveries were expressed as a percentage of non-injection baseline control and then averaged, a one-way repeated measures ANOVA was applied for each solution. For post-hoc multiple comparisons, the data were analyzed with a Dunnett's test with saline as the control.

For the ethanol fluid delivery data, in which NTX $(0.1 \mathrm{mg} / \mathrm{kg})$ was tested at different ethanol concentrations, the data were analyzed using a two-way RM ANOVA on two factors. We tested for an effect of NTX, and an interaction of NTX with ethanol concentration. Similar ANOVAs were conducted for the water fluid deliveries as well as the ethanol intake. The ethanol and water fluid delivery data had extremely large variances. To minimize the variance problem and increase the power of the test, the raw fluid delivery data were transformed to the natural log before conducting the ANOVAs. The ethanol intake data were analyzed using a twoway repeated measures ANOVA on two factors. A two-way repeated measures ANOVA was used to analyze the data produced when water was available from both spouts. All of these analyses were followed by post-hoc SNK tests. For the results of all statistical analyses cited in the results, significance refers to $P<0.05$.

\section{Experiment 2: intravenous self-administration}

\section{Subjects}

Three male rhesus monkeys served as subjects $(7.7-8.9 \mathrm{~kg})$. They were all experienced in responding for IV administration of sodium methohexital, and had been subjects in experiments involving evaluation of the reinforcing effects of other sedative drugs. They were prepared with IV silastic catheters in the internal or external jugular veins, the femoral, or brachial veins. The surgical procedure was done under ketamine $(10 \mathrm{mg} / \mathrm{kg})$ and xylazine $(2 \mathrm{mg} / \mathrm{kg})$ anesthesia using sterile surgical procedures. The implanted catheter passed subcutaneously and exited the animal at a mid-scapular site.

The animals were individually housed in primate cages measuring $83.3 \times 76.2 \times 91.4 \mathrm{~cm}$ deep. They wore tubular steel harnesses and flexible spring tethers that carried the catheters to the outside rear of the cages. In addition, they were fitted to Teflon jackets (Alice King Chatham Medical Arts, Los Angeles, Calif., USA) to reduce the likelihood that they would reach and remove their catheters.

\section{Apparatus}

Each cage contained a panel with two response levers and three stimulus lights over the levers. The two outside lights could be illuminated red; the center light could be illuminated green. The experiments were controlled by Med-Associates software (East Fairfield, Vt., USA) run on IBM PS/2 Model 70386 computers in an adjacent room.

\section{Procedure}

At the start of each of two daily 210-min sessions (one beginning at 1000 hours and one beginning at 1600 hours), one of the red lights was illuminated in the cage. In the presence of this light, ten responses on the lever under this light turned off the red light, turned on the green light, and started the infusion pump (WatsonMarlow Model MHRK 55, Falmouth, UK) that infused solution through the indwelling catheter. Under baseline conditions, this solution was either $0.1 \mathrm{mg} / \mathrm{kg}$ methohexital or saline with nearly equal frequency. Under test conditions, the solution was 0.01 , 0.032 , or $0.1 \mathrm{~g} / \mathrm{kg}$ ethanol. Doses were tested two to five times in each monkey. Test conditions were scheduled no more frequently than every fourth session, and then only if the animals showed stable levels of responding during intervening methohexital sessions and saline sessions.

Once dose-response curves with ethanol had been obtained in each monkey, several of the ethanol doses were made available again, $30 \mathrm{~min}$ following an IM injection of NTX $0.1 \mathrm{mg} / \mathrm{kg}$. This dose of NTX was tested once in each monkey. Saline pretreatments were not given.

\section{Drugs}

Ethanol solutions were prepared by mixing appropriate volumes of $95 \% \mathrm{w} / \mathrm{v}$ ethanol and tap water in oral studies or sterile water in the IV studies. Sucrose solutions consisted of granulated cane sugar dissolved in tap water. Solutions were presented at room temperature at the start of the session. Naltrexone $\mathrm{HCl}$ was supplied by NIDA and mixed with sterile water to prepare the appropriate concentrations. Methohexital (a gift from Eli Lilly and Co., Indianapolis, Ind., USA) was dissolved in sterile water. Ethanol was diluted with saline from $95 \%$ to $15 \% \mathrm{w} / \mathrm{v}$.

\section{Data analysis}

The ethanol injections, with and without NTX pretreatment, were analyzed using a two-way repeated measures ANOVA followed by a post-hoc SNK. In order to compare saline and ethanol selfadministration, one-way repeated measures ANOVAs were conducted (Fig. 7). The data for saline and the ethanol baselines, at the various ethanol doses, comprised one ANOVA, while the data for saline and ethanol following NTX comprised the other ANOVA. Post-hoc Dunnett's tests were used to compare individually the various ethanol doses with saline as the control. With all analyses, significance refers to $P<0.05$.

\section{Results}

The effects of altering the concentration of ethanol on behavior maintained by ethanol and concurrently available water are shown in Fig. 1. These ethanol concentrations produced an inverted U-shaped ethanol concentration-consumption curve and a monotonically increasing ethanol intake $(\mathrm{g} / \mathrm{kg})$ function. When water was available from both spouts, approximately equal fluid deliveries were obtained from each spout. When ethanol was avail- 

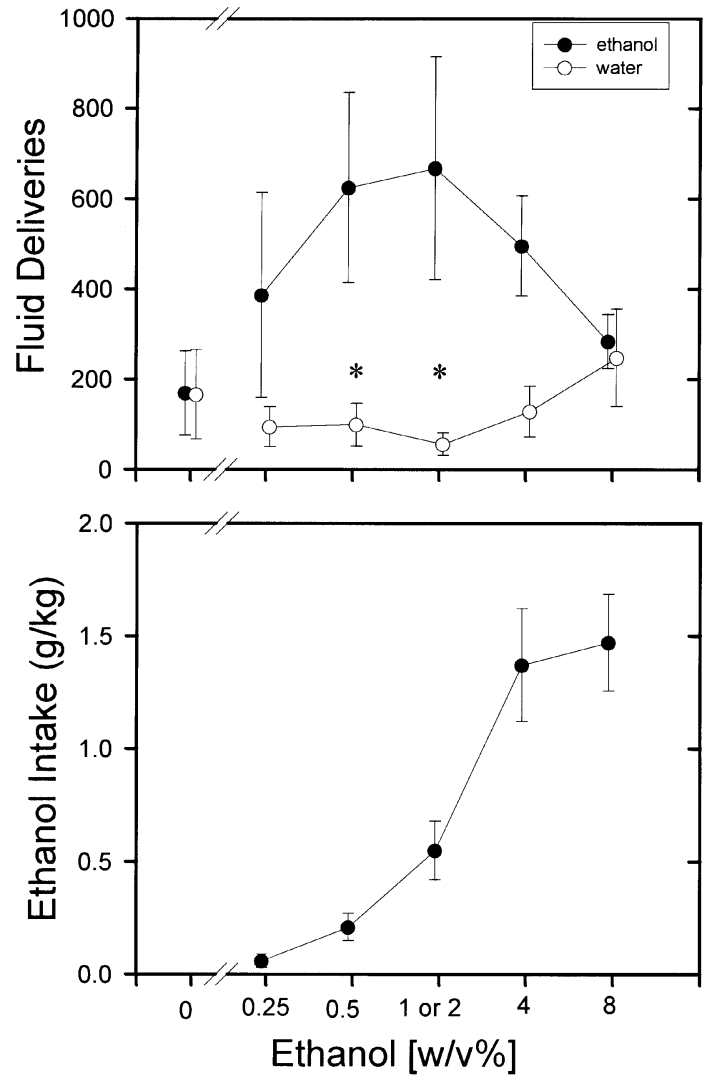

Fig. 1 Upper panel shows average number of fluid deliveries for ethanol (filled circles) and water (open circles) as the concentration of ethanol varied from $0 \%$ to $8 \%$. At $0 \%$ ethanol are the baselines for water when it was available from both spouts concurrently. The concentrations of $1 \%$ and $2 \%$ are combined to represent the "peak concentration" as explained in Materials and methods. Lower panel shows the average intake in $\mathrm{g} / \mathrm{kg}$ as ethanol concentration varied (filled circles). The points represent the overall average with the standard error across five monkeys. * Indicates significant difference $(P<0.05)$ between ethanol and the concurrently available water

able from one spout, the fluid deliveries of ethanol, at $0.5 \%$ and the peak concentration, exceeded those of the concurrently available water $(F 1,4=9.33$; SNK, $q=6.64$ and $q=7.24)$. At some concentrations, ethanol maintained a greater number of fluid deliveries than when water alone was available from both spouts (at $0 \%$ ethanol). Up to a concentration of $4 \%$, ethanol maintained more than twice the fluid deliveries of the concurrently available water. Thus, ethanol, at some concentrations, served as a reinforcer and was preferred over water in these monkeys.

The ethanol intake in $\mathrm{g} / \mathrm{kg}$ increased in a concentrationdependent manner (lower panel Fig. 1). At the peak concentration, the average intake was approximately $0.5 \mathrm{~g} / \mathrm{kg}$ for the 3-h session. At 4\%, the average intake was 1.4 $\mathrm{g} / \mathrm{kg}$. Giving the monkeys access to a higher concentration (8\%) did not increase the intake further. No overt signs of intoxication were observed at any ethanol concentration.

A main effect of NTX $(F 4,16=3.31)$ was found at the ethanol concentration that maintained the most behavior (peak concentration, Fig. 2). In post-hoc comparison, total
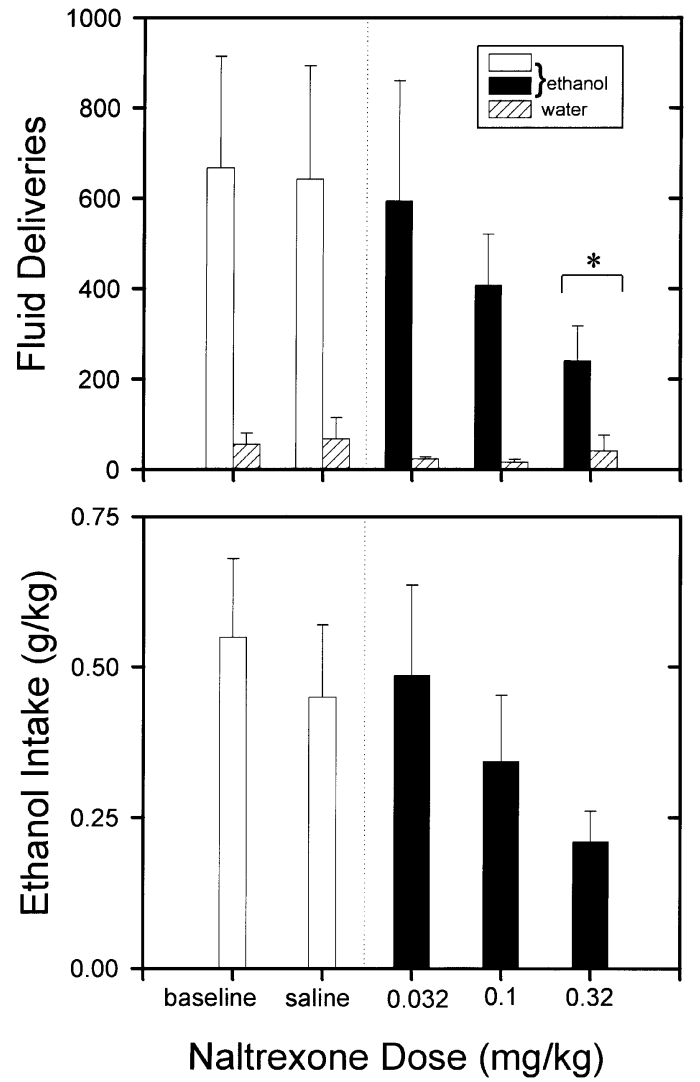

Fig. 2 Upper panel shows the average number of fluid deliveries at the peak concentration ( $1 \%$ or $2 \%$ ) of ethanol (solid bars) and water (lined bars) over different treatment days - baseline, saline, NTX doses: $0.032,0.1$, and $0.32 \mathrm{mg} / \mathrm{kg}$. Lower panel shows ethanol intake in $\mathrm{g} / \mathrm{kg}$ over the same treatments. The bars represent the overall average with the standard error across five monkeys. * Indicates total fluid consumption (ethanol and water) significantly different $(P<0.05)$ from saline

fluid deliveries (ethanol and water summed together) following the largest dose of NTX were reduced compared to the total fluid deliveries following saline (Dunnett's $\left.q^{\prime}=2.94\right)$. The interaction effect of solution and NTX narrowly missed significance $(F 4,16=2.75, P=0.065)$, which prevented statistical determination of whether the effect on total fluid deliveries was due to a selective reduction in ethanol fluid deliveries. Subsequently, in a similar experiment with different subjects, we repeatedly administered $0.1 \mathrm{mg} / \mathrm{kg}$ NTX and found a significant and selective reduction of ethanol consumption.

Cumulative records of ethanol drinking for individual sessions showed that the monkeys drank rapidly and consistently for the first 40-60 min under non-injection baseline and saline conditions (data not shown). Thereafter, short bouts of drinking were followed by non-drinking intervals until the end of the session. When pretreated with NTX $(0.32 \mathrm{mg} / \mathrm{kg}$ and in some cases $0.1 \mathrm{mg} / \mathrm{kg})$ the drinking was consistent for the first 10-20 min and then tapered off. Thus, after receiving NTX, the monkeys stopped drinking earlier in the session and had fewer drinking bouts throughout the remainder of the session. 

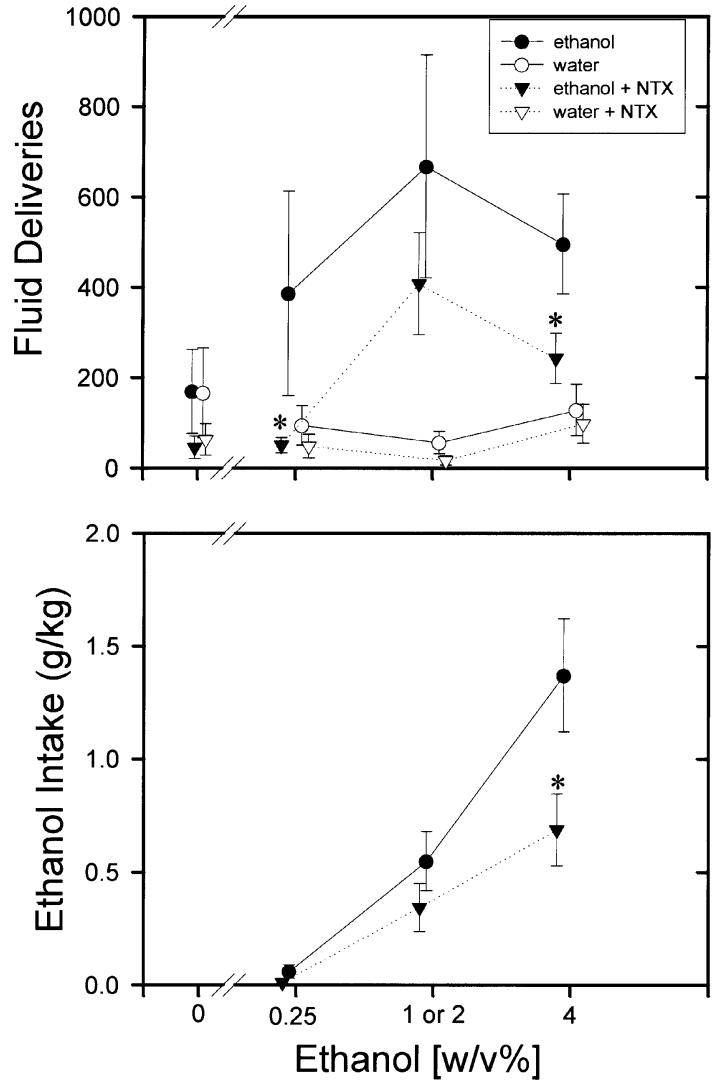

Fig. 3 Upper panel shows the average number of fluid deliveries for ethanol (filled circles) and water (open circles) at the concentrations of ethanol at which NTX was tested $(0 \%, 0.25 \%, 1$ or $2 \%$, $4 \%$ ). After $0.1 \mathrm{mg} / \mathrm{kg} \mathrm{NTX}$, ethanol is shown as closed inverted triangles (with dotted line) and water as open inverted triangles (with dotted line). The lower panel shows the average intake in $\mathrm{g} / \mathrm{kg}$ at the concentrations tested (same symbols). The points represent the overall average with the standard error across five monkeys. * Indicates significant difference $(P<0.05)$ from the baseline values

Ethanol intake in $\mathrm{g} / \mathrm{kg}$ was not affected by administration of saline or the smallest dose of NTX (lower panel Fig. 2). Increasing doses of NTX reduced ethanol intake $(F 4,16=3.14)$, but the subsequent Dunnett's test failed to reveal which NTX doses were different from saline.

Following NTX administration, fluid deliveries of ethanol at $0.25 \%$ and $4 \%$ (Fig. 3) were reduced compared to their respective baseline fluid deliveries $(F 3,12=6.04$; SNK, $q=9.11$ and $q=3.98$ ). There was a main effect of NTX on fluid deliveries of the water that was concurrently available with ethanol $(F 3,12=12.35)$. Because the interaction effect of NTX and solution was not significant for water $(P=0.09)$, we were unable to determine the ethanol concentration at which the water, following NTX, was different from the water at baseline. When water was available from both spouts (at $0 \%$ ), the reduction in fluid deliveries following NTX was not significant $(F 2,8=2.67$; $P=0.129)$. At $4 \%$, ethanol intake $(\mathrm{g} / \mathrm{kg})$, shown in the bottom panel of Fig. 3, was decreased after NTX pretreatment $(F 1,4=12.1$; SNK, $q=8.87)$.

The sucrose (100 g/l) fluid deliveries (Fig. 4) following administration of both, 0.1 and $0.32 \mathrm{mg} / \mathrm{kg}$ NTX,
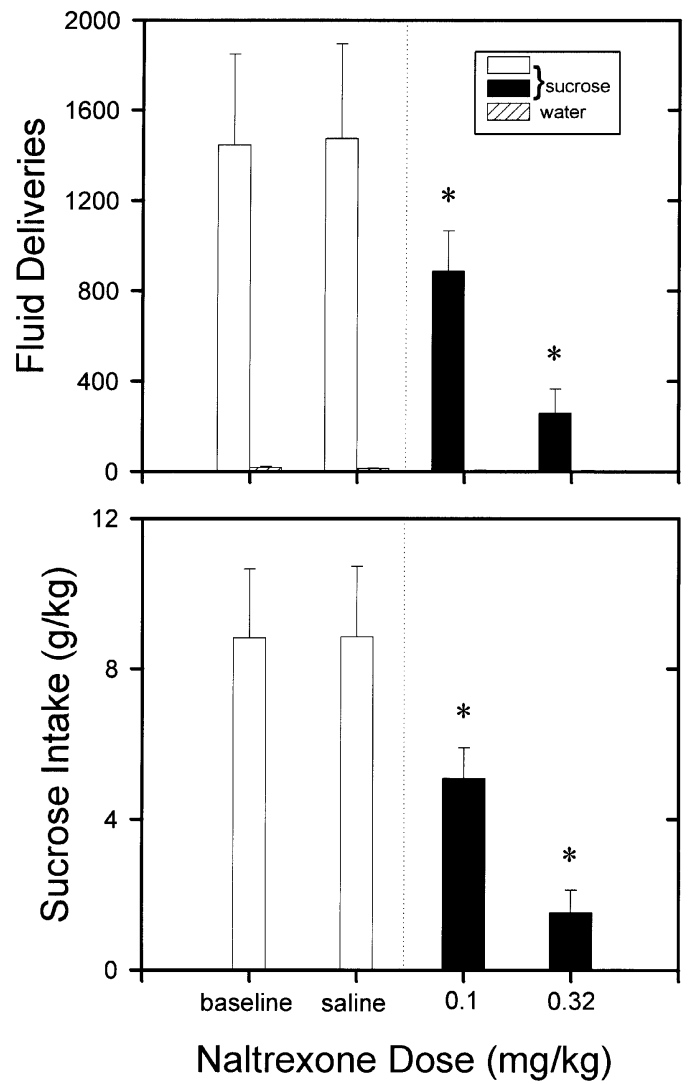

Fig. 4 Upper panel shows the average number of fluid deliveries at the peak concentration $(100 \mathrm{~g} / \mathrm{l})$ of sucrose (filled bars) and water (lined bars) over different treatment days - baseline, saline, NTX doses: 0.1 and $0.32 \mathrm{mg} / \mathrm{kg}$. The lower panel shows sucrose intake in $\mathrm{g} / \mathrm{kg}$ over the treatments. The bars represent the overall average with the standard error across five monkeys. * Indicates a significant difference $(P<0.05)$ from saline

was less than the sucrose fluid deliveries following saline administration $(F 3,12=9.74 ; \quad S N K, q=4.50$ and $q=9.32$ ). The number of sucrose fluid deliveries were more than twice that of the peak concentration of ethanol (1445 versus 668). The average fluid deliveries of the concurrently available water was almost zero. Following administration of both doses of NTX, sucrose intake $(\mathrm{g} / \mathrm{kg})$, was reduced compared with that following saline $\left(F 3,12=16.5\right.$; Dunnett's, $q^{\prime}=3.09$ and $\left.q^{\prime}=6.00\right)$.

In Fig. 5, the ethanol and sucrose fluid delivery data are expressed as a percent of non-injection baseline control, following saline or NTX administration for each monkey. Across all monkeys, the ethanol fluid deliveries following the highest dose of NTX were reduced to a similar extent (range $=31-42 \%$ of baseline control), even though the average number of baseline fluid deliveries varied greatly (range $=161-1614$ ). The sucrose data were also similar across monkeys. In four of five monkeys, the reductions in sucrose fluid deliveries following 0.32 NTX were almost identical (range $=6-9 \%$ of baseline control). Thus, NTX produced a comparable effect in all monkeys, regardless of the actual number of baseline fluid deliveries of ethanol or sucrose. 


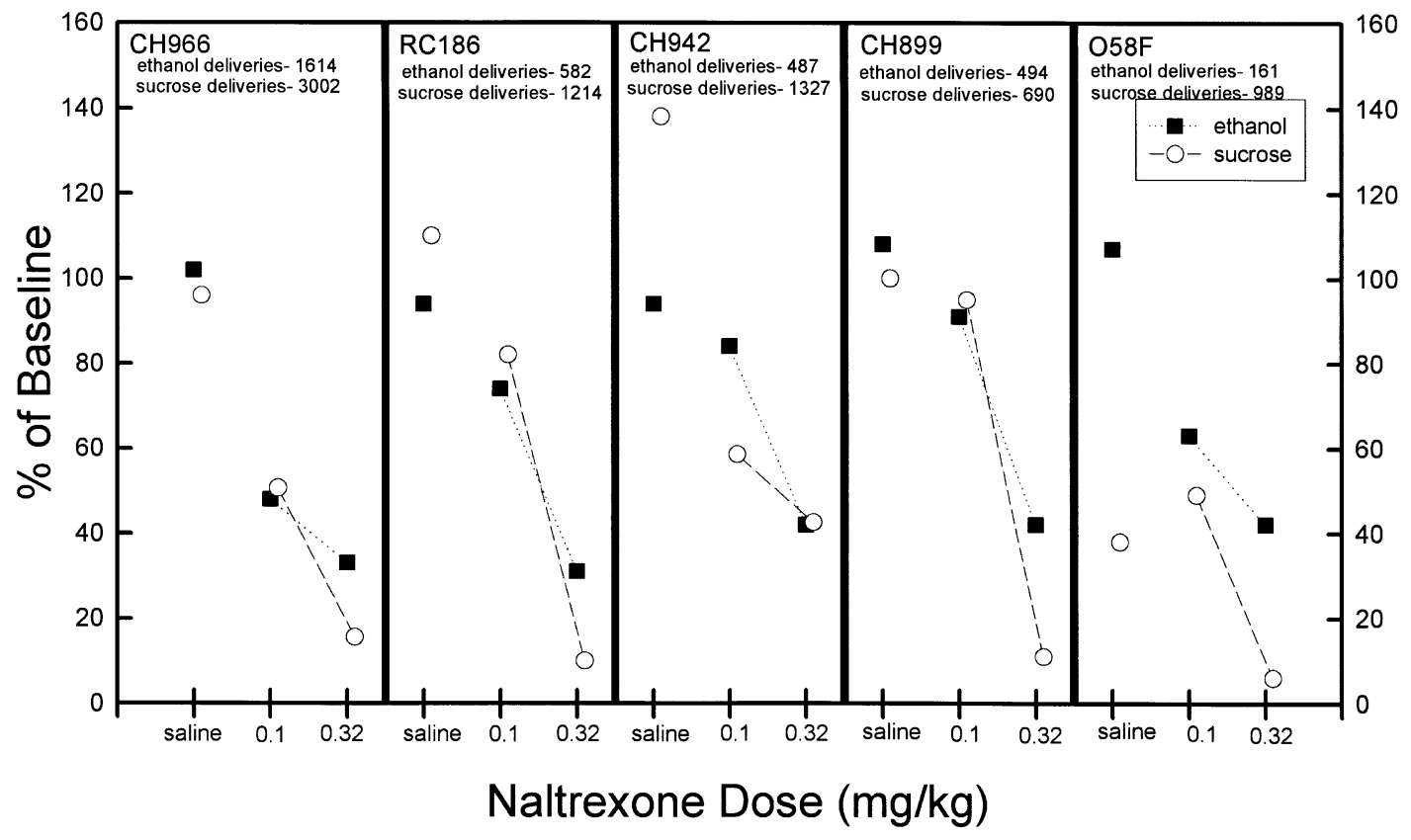

Fig. 5 Fluid deliveries of ethanol and sucrose, at the peak concentrations, expressed as a percentage of non-injection baseline control over the various treatment days - saline, NTX doses: 0.1 , and $0.32 \mathrm{mg} / \mathrm{kg}$. The five panels show the individual data for each monkey, with the points representing the individual monkey's average at that treatment. The average number of ethanol (filled squares) and sucrose (open circles) fluid deliveries at baseline for each monkey is shown at the top of each panel. The peak ethanol concentration was $1 \%$ for $\mathrm{CH} 966, \mathrm{RC} 186$, and $\mathrm{CH} 942$; and $2 \%$ for $\mathrm{CH} 899$ and $\mathrm{O} 58 \mathrm{~F}$

Fig. 6 The left panel shows the average number of fluid deliveries for ethanol at the peak concentration (1 or $2 \%$ ) expressed as a percentage of non-injection baseline control over the various treatment days - saline, NTX doses: 0.1 and $0.32 \mathrm{mg} / \mathrm{kg}$. The right panel shows the average number of fluid deliveries for sucrose at the peak concentration $(100 \mathrm{~g} / \mathrm{l})$ expressed as a percent of non-injection baseline control over the various treatment days - saline, NTX doses: 0.1 and $0.32 \mathrm{mg} / \mathrm{kg}$. The individual percentages of baseline data from Fig. 5 were compiled and averaged. The bars represent the overall average and standard error across five monkeys. * Indicates a significant difference $(P<0.05)$ from the saline treatment for each respective fluid
When ethanol and sucrose fluid deliveries, expressed as a percentage of non-injection baseline control, were averaged and compared to one another, the effects of NTX were similar (Fig. 6). For the ethanol data, only the effect following administration of $0.32 \mathrm{mg} / \mathrm{kg}$ NTX was significantly different from that following saline (F3,12=6.47; Dunnett's, $\left.q^{\prime}=4.19\right)$. The $0.032 \mathrm{mg} / \mathrm{kg}$ dose of NTX was included in the statistical analysis for ethanol, but for comparison with sucrose, only the two larger doses of NTX are shown in Fig. 6. For sucrose, both doses of NTX produced an effect that was significantly different from saline $\left(F 2,8=32.7\right.$; Dunnett's, $q^{\prime}=3.24$ and $\left.q^{\prime}=8.04\right)$. Although NTX $0.1 \mathrm{mg} / \mathrm{kg}$ had a non-significant effect on ethanol and a significant effect on sucrose, the reductions of ethanol and sucrose were analogous (72\% versus $67 \%$ of baseline control). At the highest NTX dose, NTX was slightly less effective in reducing ethanol than sucrose consumption (38\% versus $17 \%$ of baseline control, respectively).

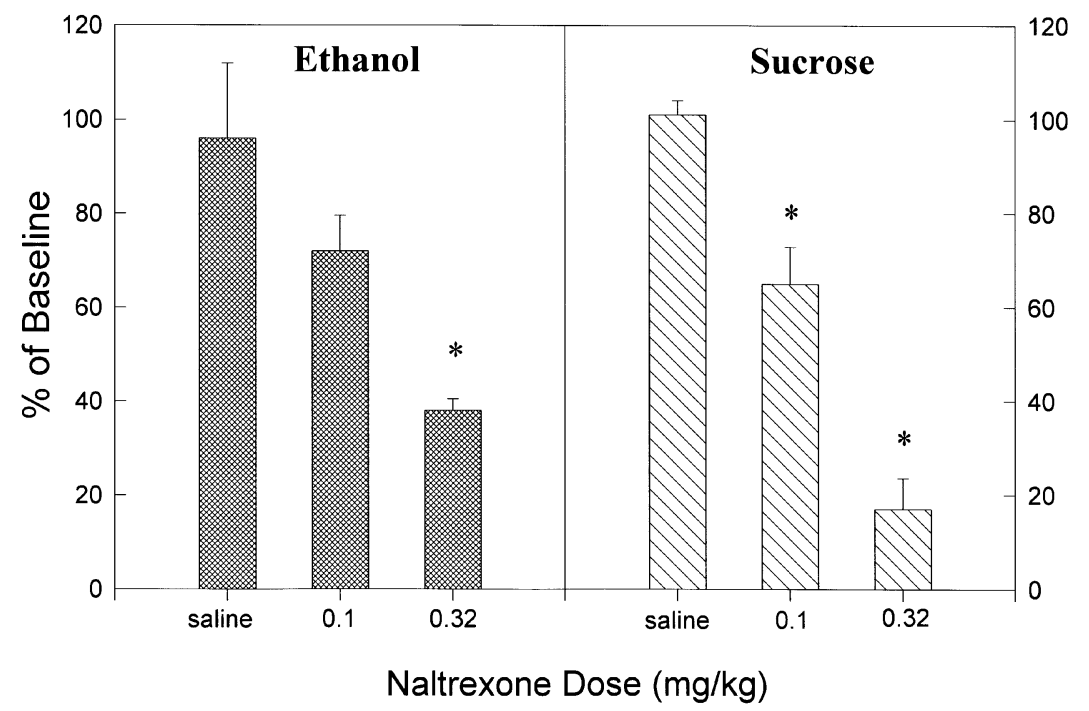




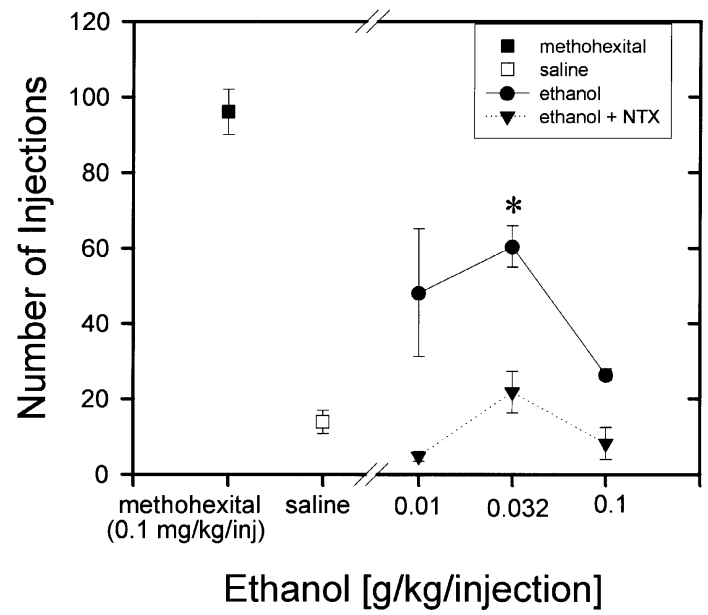

Fig. 7 The number of IV injections obtained is plotted across methohexital $0.1 \mathrm{mg} / \mathrm{kg}$ per injection (filled square), saline (open square), and ethanol $0.01,0.032$, and $0.1 \mathrm{~g} / \mathrm{kg}$ per injection (filled circles). The number of injections of ethanol following NTX 0.1 $\mathrm{mg} / \mathrm{kg}$ is also depicted (inverted filled triangles). The points represent the overall average and standard error across three monkeys. * Indicates the number of injections of ethanol was significantly greater than the number of injections of saline

The data for the IV experiment are shown in Fig. 7. In these monkeys, with a history of both methohexital- and saline-maintained responding, a substantial number of injections of methohexital were taken, and few injections of saline were taken, indicating a good discrimination between a reinforcing drug and its vehicle. All doses of ethanol maintained a lower number of injections than the reference dose of methohexital $(0.1 \mathrm{~g} / \mathrm{kg}$ per injection), however, only one dose of ethanol $(0.032 \mathrm{~g} / \mathrm{kg}$ per injection) maintained significantly more injections than did saline $\left(F 3,11=5.27\right.$; Dunnett's, $\left.q^{\prime}=5.27\right)$. Overall, NTX reduced the number of ethanol injections obtained $(F 1,4=56.38$; SNK, $q=10.6)$. Since the interaction of ethanol and NTX was not significant, we were unable to determine at which ethanol dose the number of injections were reduced by NTX. After NTX treatment, the number of ethanol injections at the three doses tested was not different from the number of saline injections $(F 3,11=3.17$; $P=0.11)$.

\section{Discussion}

Previous research has shown that ethanol serves as a reinforcer via the oral and IV route (Meisch and Stewart 1994). In the present experiments, we also demonstrated that ethanol served as an oral and IV reinforcer in monkeys. The opioid antagonist, NTX, reduced the operant behavior maintained by ethanol regardless of its route of administration. NTX also reduced the responding maintained by a sucrose solution. The interaction of NTX with ethanol was not of the classical opioid agonist/competitive antagonist interaction; in these experiments, NTX produced an insurmountable reduction in ethanol- reinforced responding when ethanol was delivered via the oral or IV route. The interaction of NTX with the reinforcers used in this study is unclear. NTX appears to reduce the effect of a variety of reinforcers under some conditions, but the mechanism by which it does so is not apparent.

NTX may affect ethanol consumption by blocking the reinforcing effects of ethanol. Some researchers suggest that ethanol's reinforcing properties are mediated by the endogenous opioid system (Gianoulakis 1994; Ulm et al. 1995). Ethanol may stimulate the endogenous opioid system by: (1) causing the release of endogenous opioids, (2) modifying the sensitivity of opioid receptors, or (3) producing a metabolic byproduct that is active at opioid receptors. Regardless of the mechanism by which the endogenous opioid system is stimulated by ethanol, the pharmacological endpoint is the activation of opioid receptors. Thus, the effects of a competitive antagonist, such as NTX, should be surmountable by increasing further the activity at opioid receptors. To address the issue of surmountability of the NTX effect, we examined the effect of NTX at various ethanol concentrations (oral) or doses (IV). Under certain conditions, NTX appeared to reduce ethanol-reinforced responding at all three ethanol concentrations or doses. In both ethanol experiments, NTX shifted the ethanol dose-effect curve down. If this were a classical opioid agonist/competitive antagonist interaction, the effect of the antagonist could be overcome by increasing the dose of the agonist. For example, in the IV self-administration of opioid agonists, competitive opioid antagonists produce a surmountable rightward shift of the potency of the agonist (Winger et al. 1992). In our experiments, NTX continued to decrease ethanol consumption even though the monkeys had the opportunity to increase substantially their ethanol intake $(\mathrm{g} / \mathrm{kg})$ when larger concentrations or doses available. Hence, regardless of the route of ethanol self-administration, the interaction between NTX and ethanol was not comparable to that of an opioid agonist/competitive antagonist.

The effect of NTX on reinforced responding was not selective for ethanol. Other research has demonstrated that opioid antagonists reduced consumption of water, flavored solutions, and food (Reid 1985). In our experiments, we examined the effect of NTX on oral sucrosereinforced responding and found that NTX decreased sucrose fluid deliveries. Also, when NTX was administered with water as the only available fluid, it non-significantly reduced water consumption from both spouts. These data support the notion that NTX's effect on ethanol consumption may be due to a mechanism that modulates consumption in general.

The effect of NTX on oral ethanol or sucrose consumption may be due to satiety factors. Some researchers have analyzed the temporal pattern of drinking after administration of NX in rats (Brown and Holtzman 1981; Siviy et al. 1982). They found no effect on the latency to begin drinking, but the drinking decreased several minutes after the session began. These patterns of 
drinking were similar to those of water preloaded rats (Cooper 1982), suggesting an effect of NX on satiety by increasing it or bringing it forward in time. In our experiments, the session cumulative records indicated that the monkeys started to respond for fluid normally, but obtained less total fluid by simply stopping earlier in the session.

Not completely unrelated to satiation, NTX may effect the palatability of the fluids consumed. In our experiments, NTX may have been slightly more effective in reducing consumption of sucrose compared to the peak concentration of ethanol. Sucrose may be considered more palatable; it maintained more than twice the fluid deliveries of ethanol. NTX $0.1 \mathrm{mg} / \mathrm{kg}$ produced a significant reduction of sucrose, but not ethanol solutions. Also, at the larger NTX dose, the reduction was greater for sucrose compared with ethanol. At various ethanol concentrations, the effect of NTX is more complex. NTX $0.1 \mathrm{mg} / \mathrm{kg}$ significantly reduced ethanol fluid deliveries at $0.25 \%$ and $4 \%$, but not at the peak concentration. Consumption was reduced at these ethanol concentrations even though the ethanol intake $(\mathrm{g} / \mathrm{kg})$ was almost zero at $0.25 \%$ and close to $1.5 \mathrm{~g} / \mathrm{kg}$ at $4 \%$. This evidence suggests that ethanol intake $(\mathrm{g} / \mathrm{kg})$ is not related to the ability of NTX to reduce consumption. In addition, the palatability explanation fails to account for the NTX-induced reductions in self-administered IV ethanol. Although it is likely that monkeys can taste ethanol delivered IV, it is unlikely that this taste is strongly related to ethanol's ability to maintain behavior by this route, or that modification of this taste would result in the marked decreases in responding that we observed here.

NTX may induce nausea or other aversive effects which may interfere with consummatory behaviors. NTX has been shown to produce conditioned place aversion in rats (Parker and Rennie 1992) and some participants receiving NTX in the human studies reported feeling sick (O'Malley et al. 1992; Volpicelli et al. 1992). In the oral experiments, the monkeys reduced consumption on the day of NTX injection, but drank at control levels on subsequent days. Conditioned aversion was not produced in our experiments, probably due to the extensive pre-exposure to the solutions. However, nausea may be the result of an interaction of NTX and ethanol (or sucrose) consumption. This interaction-induced nausea helps to explain why consumption was reduced only on the day of injection as well as the lack of effect on the latency to begin drinking. If NTX alone produced illness or nausea, we would expect an increase in the latency to begin drinking. NTX-induced nausea or aversion needs further experimental attention.

As discussed earlier, NTX has been successful in treating alcohol dependence in clinical trials (O'Malley et al. 1992; Volpicelli et al. 1992). Our results suggest that the therapeutic effect should not be attributed to a specific interaction between ethanol and opioids. Our study showed decreases with ethanol-, sucrose-, and water-reinforced responding. Furthermore, the interaction of NTX with ethanol was not a typical opioid ago- nist/competitive antagonist interaction. The effects were not surmountable by increasing ethanol dose or concentration. Further research using non-human primates, may help determine an appropriate mechanism by which NTX achieves its clinical results.

Acknowledgements This work was supported by USPHS grants AA-11424 and DA00254.

\section{References}

Altshuler H, Phillips P, Feinhandler D (1980) Alteration of ethanol self-administration by naltrexone. Life Sci 26:679-688

Bertino M, Beauchamp G, Engleman K (1991) Naltrexone, an opioid blocker, alters taste perception and nutrient intake in humans. Am J Physiol 261:R59-R63

Brown D, Holtzman S (1980) Evidence that opiate receptors mediate suppression of hypertonic saline-induced drinking in the mouse by narcotic antagonists. Life Sci 26:1543-1550

Brown D, Holtzman S (1981) Narcotic antagonists attenuate drinking induced by water deprivation in a primate. Life Sci 28:1287-1294

Cooper S (1982) Caffeine-induced hypodipsia in water-deprived rats: relationships with benzodiazepine mechanisms. Pharmacol Biochem Behav 17:481-487

Cooper S, Turkish S (1989) Effects of naltrexone on food preference and concurrent behavioral responses in food-deprived rats. Pharmacol Biochem Behav 33:17-20

De Witte P (1984) Naloxone reduces alcohol intake in a freechoice procedure even when both drinking bottles contain saccharin sodium or quinine substances. Biol Psychiatry 12:73-77

Fantino M, Hosotte J, Apfelbaum M (1986) An opioid antagonist, naltrexone, reduces preference for sucrose in humans. Am J Physiol 251:R91-R96

Froehlich J, Harts J, Lumeng L, Li T-K (1990) Naloxone attenuates voluntary ethanol intake in rats selectively bred for high ethanol preference. Pharmacol Biochem Behav 35:385-390

Gianoulakis C, de Waele JP (1994) Genetics of alcoholism: role of endogenous opioid system. Metab Brain Dis 9:105-131

Henningfield J, Meisch R (1976) Drinking device for rhesus monkeys. Pharmacol Biochem Behav 4:609-610

Holtzman S (1974) Behavioral effects of separate and combined administration of naloxone and $d$-amphetamine. J Pharmacol Exp Ther 189:51-60

Kirkham T, Cooper S (1988a) Attenuation of sham feeding by naloxone is stereospecific: evidence for opioid mediation of orosensory reward. Physiol Behav 43:845-847

Kirkham T, Cooper S (1988b) Naloxone attenuation of sham feeding is modified by manipulation of sucrose concentration. Physiol Behav 44:491-494

Kornet M, Goosen C, Van Ree J (1991) Effect of naltrexone on alcohol consumption during chronic alcohol drinking and after a period of imposed abstinence in free-choice drinking rhesus monkeys. Psychopharmacology 104:367-376

Locke K, Brown D, Holtzman S (1982) Effects of opiate antagonist and putative mu- and kappa-agonist on milk intake in rat and squirrel monkey. Pharmacol Biochem Behav 17:1276-1279

Maickel R, Braude M, Zabik J (1977) The effects of various narcotic agonists and antagonists on deprivation-induced fluid consumption. Neuropharmacology 16:863-866

Meisch R, Stewart R (1994) Ethanol as a reinforcer: a review of laboratory studies of non-human primates. Behav Pharmacol $5: 425-440$

Meisch R, Henningfield J, Thompson T (1975) Establishment of ethanol as a reinforcer for rhesus monkeys via the oral route: initial results. Adv Exp Med Biol 59:323-342 
Myers R, Borg S, Mossberg R (1986) Antagonism by naltrexone of voluntary alcohol selection in the chronically drinking macaque monkey. Alcohol 3:383-388

O'Malley S, Jaffe A, Chang G, Shottenfeld R, Meyer R, Rounsaville B (1992) Naltrexone and coping skills therapy for alcohol dependence. Arch Gen Psychiatry 49:881-887

Parker L, Rennie M (1992) Naltrexone-induced aversions: assessment by place conditioning, taste reactivity, and taste avoidance paradigms. Pharmacol Biochem Behav 41:559-565

Reid L (1985) Endogenous opioid peptides and regulation of drinking and feeding. Am J Clin Nutr 42:109-132

Sinden J, Marfaing-Jallat P, Le Magnen J (1983) The effect of naloxone on intragastric ethanol self-administration. Pharmacol Biochem Behav 19:1045-1048

Siviy S, Calcagnetti D, Reid L A (1982) Temporal analysis of naloxone's suppressant effect on drinking. Pharmacol Biochem Behav 16:173-175
Stapleton J, Ostrowski N, Merriman V, Lind M, Reid L (1979) Naloxone reduces fluid consumption in water-deprived and nondeprived rats. Bull Psychon Soc 13:237-239

Ulm R, Volpicelli J, Volpicelli L (1995) Opiates and alcohol selfadministration in animals. J Clin Psychiatry 56 [suppl 7]: 5-14

Volpicelli J, Alterman A, Hayashida M, O'Brien C (1992) Naltrexone in treatment of alcohol dependence. Arch Gen Psychiatry 49:876-880

Volpicelli J, Watson N, King A, Sherman C, O'Brien C (1995) Effect of naltrexone on alcohol "high" in alcoholics. Am J Psychiatry 152:613-615

Winger G, Skjoldager P, Woods JH (1992) Effects of buprenorphine and other opioid agonists and antagonists on alfentaniland cocaine-reinforced responding in rhesus monkeys. J Pharmacol Exp Ther 261:311-317 